\title{
INCREASED NITRIC OXIDE LEVELS IN EXHALED AIR OF RAT LUNG ALLOGRAFTS
}

Takatoshi Mizuta, MD

Yoshitaka Fujii, MD

Masato Minami, $\mathrm{MD}^{\mathrm{a}}$

Satonori Tanaka, $\mathrm{MD}^{\mathrm{a}}$

Tomoki Utsumi, $\mathrm{MD}^{\mathrm{a}}$

Hiroaki Kosaka, MD ${ }^{\text {b }}$

Ryouta Shirakura, $\mathrm{MD}^{\mathrm{c}}$

Hikaru Matsuda, MD $^{\text {a }}$
In organ transplantation nitric oxide has been reported to be involved in allograft rejection. We examined in a rat lung transplantation model whether nitric oxide is overproduced in acute rejection and can be detected in exhaled air. Thirteen rat right lung transplants were separated into three groups: group $1(n=5)$, untreated allografts (Brown-Norway $\left[\mathrm{RT}^{\mathrm{n}}\right]$ to Lewis [RT1 $\left.\left.{ }^{\mathrm{l}}\right]\right)$; group $2(n=4)$, cyclosporine-treated allografts; and group $3(n=4)$, isografts (Lewis to Lewis). We examined exhaled nitric oxide levels with a chemiluminescence analyzer and chest roentgenograms on days 2 through 5. Histologic samples were obtained on days 3 and 5. On day 5 , the recipients were killed and we measured exhaled nitric oxide from the right and left lungs separately. Blood samples were also obtained for measurement of serum nitrite/nitrate. The exhaled nitric oxide level in untreated allografts increased significantly from day $5(63.9 \pm 39.2 \mathrm{ppb}$, $p=0.0095)$ and was significantly higher than that in treated allografts $(9.1 \pm 1.6 \mathrm{ppb})(p=0.0085)$ and isografts $(6.9 \pm 0.5 \mathrm{ppb})(p=0.0068)$. The nitric oxide level in untreated allografts $(826.5 \pm 416.1 \mathrm{ppb})$ was 75 times as high as that from the contralateral normal left lungs $(11.2 \pm 2.6 \mathrm{ppb})$ $(p=0.0118)$. The level of exhaled nitric oxide correlated significantly with the histologic rejection grade $(p=0.0001)$. There was no significant difference in the serum nitrite/nitrate levels between allografts and isografts. These data suggest that increased exhaled nitric oxide levels might reflect acute rejection in lung transplants. ( $J$ Thorac Cardiovase Surg 1997;113:830-5)
$\mathrm{N}$ itric oxide (NO) has been reported to be involved in allograft rejection in experimental vascularized organ transplants such as heart, ${ }^{1}$ kidney, ${ }^{2}$ and pancreas. ${ }^{3}$ In those reports, NO was detected in the serum or urine by measurement of the stable end products nitrite/nitrate as indirect markers of NO in accordance with acute rejection. In lung transplantation, Shiraishi and colleagues ${ }^{4}$ reported that the serum nitrite/nitrate level increased during acute rejection and that administration of aminoguanidine, an inhibitor of inducible

From the First Department of Surgery ${ }^{\mathrm{a}}$ and First Department of Physiology, ${ }^{b}$ Osaka University Medical School, Osaka, and the Division of Organ Transplantation, Biomedical Research Center, ${ }^{c}$ Suita, Japan.

Received for publication August 1, 1996; revisions requested Oct. 14, 1996; revisions received Nov. 13, 1996; accepted for publication Dec. 27, 1996.

Address for reprints: Takatoshi Mizuta, MD, First Department of Surgery, Osaka University Medical School, 2-2 Yamadaoka, Suita, Osaka, 565, Japan.

Copyright (C) 1997 by Mosby-Year Book, Inc.

$0022-5223 / 97 \$ 5.00+0 \quad \mathbf{1 2 / 1 / 8 0 1 0 5}$
NO synthetase (iNOS), prolonged lung graft survival as assessed by radiographic and histologic findings.

Recently endogenous NO, formed in the respiratory system, has been detected in exhaled air from human beings ${ }^{5}$ and animals ${ }^{6}$ in such conditions as untreated bronchial asthma and in endotoxintreated rats as a septic model. If the lung itself overproduces $\mathrm{NO}$ at the time of acute rejection, it is hypothesized that NO can be detected in exhaled air and the measurement of exhaled NO might work as a noninvasive marker of acute rejection. Therefore we examined whether NO could be detected in exhaled air at acute rejection and whether administration of conventional immunosuppressants could suppress the increase in exhaled NO levels.

\section{Material and methods}

Thirteen orthotopic right single lung transplantation procedures were performed with use of weight-matched pairs (250 to $350 \mathrm{gm}$ ) of male inbred Brown-Norway $\left(\mathrm{RT}^{\mathrm{n}}\right)$ and Lewis $\left(\mathrm{RT}^{1}\right)$ rats purchased from Charles River Japan, Inc. (Yokohama). The transplants consisted of three groups: group $1(n=4)$, untreated allografts 
(Brown-Norway to Lewis); group $2(n=5)$, cyclosporinetreated allografts $(25 \mathrm{mg} / \mathrm{kg}$ intramuscularly on days 3 and 4 ); and group $3(n=4)$, isograft control transplants (Lewis to Lewris).

Surgical procedure. Right single lung transplantation in the rat was performed according to the method described in our previous report. ${ }^{7}$ Briefly, the rats were anesthetized with intraperitoneal administration of pentobarbital $(20 \mathrm{mg} / \mathrm{kg})$ after intramuscular injection of atropine $(0.25 \mathrm{mg} / \mathrm{kg})$ and ketamine $(25 \mathrm{mg} / \mathrm{kg})$. The donor was placed in the supine position and the lungs ventilated with room air through a tracheostomy tube with a tidal volume of $10 \mathrm{ml} / \mathrm{kg}$, a respiratory rate of 60 breaths/min, and a positive end-expiratory pressure of 1.0 $\mathrm{cm} \mathrm{H}_{2} \mathrm{O}$. Heparin (1000 units $/ \mathrm{kg}$ ) was injected intravenously and a laparotomy was performed to exsanguinate the donors by severing the abdominal aorta and inferior vena cava. The thorax was exposed through a median sternotomy. Pulmonary arterial flush was not performed. The heart-lung block was extracted with the lungs inflated at end tidal volume and immersed in $4^{\circ} \mathrm{C}$ saline solution. We used a cuff technique for three vascular anastomoses: the right main pulmonary artery, a superior pulmonary vein, and an inferior pulmonary vein. The dissected right lung, with attached cuffs, was preserved in $4^{\circ} \mathrm{C}$ heparinized saline solution until the recipient was prepared. The recipient was placed in the left lateral decubitus position after orotracheal intubation and a right thoracotomy was performed in the fifth intercostal space. The right hilum was dissected and the graft vessels with cuffs were anastomosed with circumferential 6-0 silk sutures. The right main bronchus was anastomosed with 8-0 Prolene polypropylene running suture and the thorax was closed in three layers with a chest tube left in place. The chest tube and the endotracheal tube were removed after spontaneous ventilation resumed. The animals were set free breathing room air.

Assessment. Preliminary experiments showed this allograft combination resulted in the completion of allograft rejection as assessed roentgenologically by day 7 . The peak concentration of exhaled NO occurred on day 5 as a result of uneven ventilation because of decreasing compliance of the allograft in accordance with the progression of acute rejection. We examined exhaled NO levels and the chest radiograph on days 2 through 5 . The method of NO measurement is described in a following section. On day 3, all recipients underwent repeat thoracotomy through the previous incision and the right upper lobe was extracted as a sample for histologic assessment after radiographic assessment and measurement of the exhaled NO level with inhalation of enflurane. On day 5, the recipients were killed to obtain the exhaled NO concentration from both lungs and from the right and left lungs separately 30 minutes after circulatory arrest. Blood samples were also obtained through an arterial line. The rest of the right lung was extracted for histologic assessment.

Ventilation score. The lungs in all recipients were assessed radiographically each day from days 2 through 5 before collection of exhaled air; the assessment was done according to the ventilation score of Prop and associates ${ }^{8}$ by a blinded coworker. Briefly, scores were determined by the sum of the aerated surface score ( 0 to 3 ) and the density score ( 0 to 3 ) of the right lung ( 6 for normalappearing lungs to 0 for opaque lungs).

Morphology. For histologic study the right upper lobe was removed on day 3 and the lower and postcaval lobes were removed on day 5 after collection of the gas samples. Specimens were fixed with $20 \%$ neutralized formalin. Paraffin sections were stained with hematoxylin and eosin stain for examination under a light microscope and histologic rejection grades were scored by a blinded observer according to the international working formulation": grade $\mathrm{A} 0$, no significant abnormality; grade $\mathrm{A} 1$, scattered infrequent perivascular mononuclear infiltration; grade A2, frequent perivascular mononuclear infiltration; grade A3, extension of mononuclear infiltration into alveolar septum/spaces; and grade A4, diffuse perivascular, interstitial, and air space infiltration of mononuclear cells.

Measurement of exhaled NO. Recipients were placed under general anesthesia with inhalation of enflurane and intubated with a 14-gauge venous cannula orotracheally. Mandatory ventilation consisting of $5 \mathrm{ml}$ of room air was done 10 times with a $10 \mathrm{ml}$ syringe. The last $5 \mathrm{ml}$ of exhaled air collected in the syringe was subjected to $\mathrm{NO}$ analysis. Three successive $1 \mathrm{ml}$ exhaled air samples were measured with a chemiluminescence analyzer (Sievers model $270 \mathrm{~B}$ ) sensitive to NO at concentrations from 5 to $5 \times 10^{5} \mathrm{ppb}$ by volume within 30 minutes after collection of exhaled air. The average of the data from the three successive samples was used in analysis.

Measurement of nitrite/nitrate. The $1.5 \mathrm{ml}$ of heparinized blood collected at the time the animals were killed was centrifuged at $1200 \mathrm{~g}$, and the plasma fraction was diluted 1:1 with nitrite- and nitrate-free distilled water. Subsequently, $400 \mu \mathrm{l}$ of diluted plasma was ultrafiltered at $2000 \mathrm{~g}$ (Ultrafree MC microcentrifuge device, UFC3 LGC, Millipore, Bedford, Mass.). The filtrates were analyzed by an automated procedure based on the Griess reaction. ${ }^{10}$

Statistical analysis. All data are presented as mean plus or minus the standard deviation. Analysis of variance was used for follow-up of exhaled NO and nitrite/nitrate levels. Comparisons of ventilation score and rejection grade were analyzed by Mann-Whitney U test. The Spearman rank correlation test was used for analysis between exhaled NO level and ventilation score or rejection grade.

All animals received humane care in compliance with recommendations of the National Academy of Sciences. ${ }^{11}$

\section{Results}

The concentrations of exhaled NO in cyclosporine-treated allografts and isografts were consistently less than $11 \mathrm{ppb}$ throughout the postoperative days, whereas those in untreated allografts increased significantly to day $5(63.9 \pm 39.2 \mathrm{ppb}, p=0.0095)$ and these values were significantly higher than those in isografts (6.9 $\pm 0.5 \mathrm{ppb} ; p=0.0068)$ and cyclosporine- treated allografts $(9.1 \pm 1.6 \mathrm{ppb} ; p=0.0085)$ (Fig. 1). After exsanguination, exhaled NO levels increased both in the untreated allografts from $63.5 \pm 9.2 \mathrm{ppb}$ to $227.8 \pm 154.8 \mathrm{ppb}(p=0.06)$ and in cyclosporine-treated allografts from $9.1 \pm 1.6 \mathrm{ppb}$ 


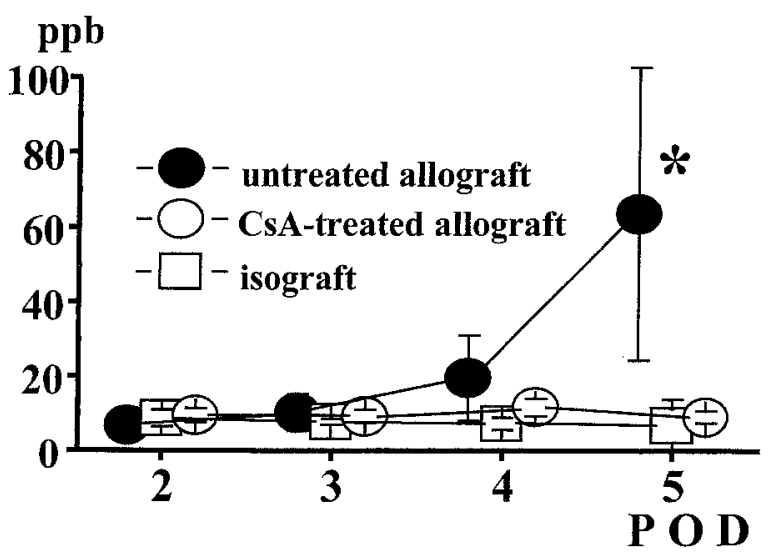

Fig. 1. Exhaled NO concentrations from untreated allografts $(n=5)$, cyclosporine (Cs $A)$-treated allografts $(n=$ $4)$, and control isografts $(n=4)$. *Significant difference from untreated allografts on postoperative days $(P O D) 2$ through $4(p=0.0095)$ and on day 5 for isografts $(p=$ $0.0068)$ and cyclosporine-treated allografts $(p=0.0085)$.

to $16.9 \pm 3.4 \mathrm{ppb}(p=0.07)$ (Fig. 2). In the untreated allografts the exhaled NO concentration from the right lung $(826.5 \pm 416.1 \mathrm{ppb})$ was 75 times as high as that from the left $(11.2 \pm 2.6 \mathrm{ppb})(p=$ 0.0118 ). Cyclosporine-treated animals also showed significant differences between the NO concentrations from the right $(27.9 \pm 10.6 \mathrm{ppb})$ and left $(10.7 \pm 2.9 \mathrm{ppb})$ grafts $(p=0.0199)$ (Fig. 3). Although the ventilation score significantly decreased from day $3(4.8 \pm 0.8)(p=0.005)$ and day $4(4.0 \pm 1.1)(p=0.0182)$ to day $5(3.0 \pm 0.0)$ in the untreated allografts, there was no statistical correlation between the value of exhaled NO and the ventilation score in either untreated or treated allografts (Fig. 4). In contrast, the histologic rejection grade of untreated allografts significantly increased from day $3(1.2 \pm 0.5)$ to day $5(2.4 \pm 0.6)$ $(p=0.0139)$ and the concentration of exhaled NO in both untreated and treated allografts correlated significantly with the progression of acute rejection $(p=0.0001$ ) (Fig. 5, B). There was no significant difference in the serum nitrite/nitrate levels among untreated allografts $(33.4 \pm 8.2 \mu \mathrm{mol} / \mathrm{L})$, cyclosporine-treated allografts $(45.5 \pm 14.8 \mu \mathrm{mol} / \mathrm{L})$, and isografts (25.4 $\pm 6.2 \mu \mathrm{mol} / \mathrm{L}$ ) (Fig. 6).

\section{Discussion}

NO production during allograft rejection has been reported in various organs such as heart, ${ }^{1}$ kidney, ${ }^{2}$ and pancreas ${ }^{3}$ and in lung transplantation in the rat ${ }^{4}$ by measurement of systemic nitrite/

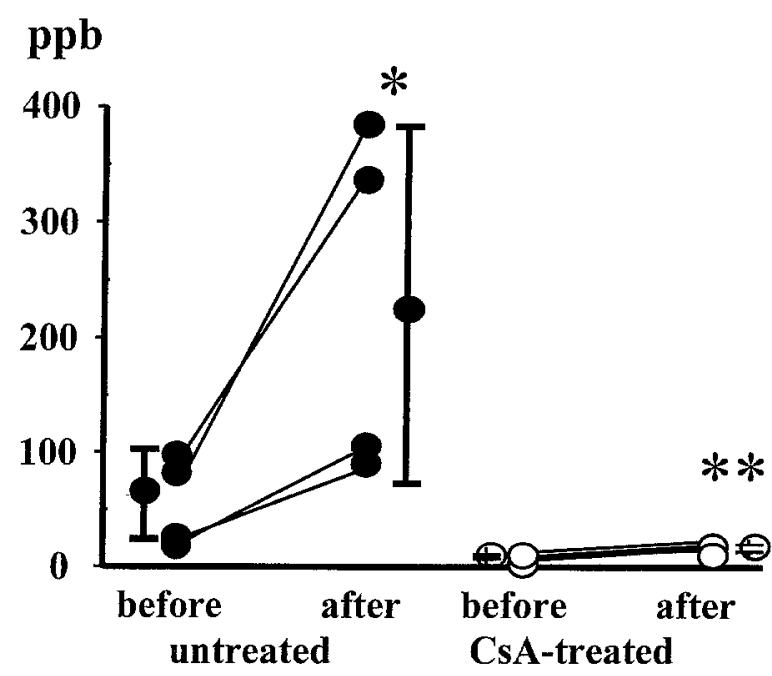

Fig. 2. Changes in exhaled NO concentrations in untreated (closed circles, $n=4)$ and cyclosporine (CSA)treated (open circles, $n=4$ ) allografts before and after the animals were killed. ${ }^{*} p=0.06 ;{ }^{* *} p=0.07$ versus before death.

nitrate, which are stable end products, in serum or urine at serial times after transplantation. Endogenous $\mathrm{NO}$ is immediately metabolized by binding to hemoglobin or oxygenation and its half life is only a few seconds in the physiologic condition. That is why the stable end products have been measured instead of NO itself. In this report, with use of a unilateral rat lung transplantation model, we were able to measure the concentration of $\mathrm{NO}$ exhaled from the allograft. The concentration of exhaled NO increased in accordance with the progression of acute rejection. There was no increase in exhaled NO levels in rats given a conventional immunosuppressant (Fig. 1). After exsanguination, NO concentrations in exhaled air increased threefold, reflecting the absence of the pulmonary circulation, which washes out the produced NO $(p=0.06)$. The concentration of exhaled NO from the grafts was significantly higher than that from the native left lungs. These findings imply that the source of produced NO was the lungs themselves and especially that most of the NO-producing sites were allografts undergoing acute rejection.

Shiraishi and colleagues ${ }^{4}$ reported a significant increase in concentration of serum nitrite/nitrate on days 4 and 7 with orthotopic left lung transplantation in a Brown-Norway to F344 (RT1 ${ }^{\text {lvl }}$ ) rat combination. Interestingly, in the present study there was no significant difference in nitrite/nitrate levels 


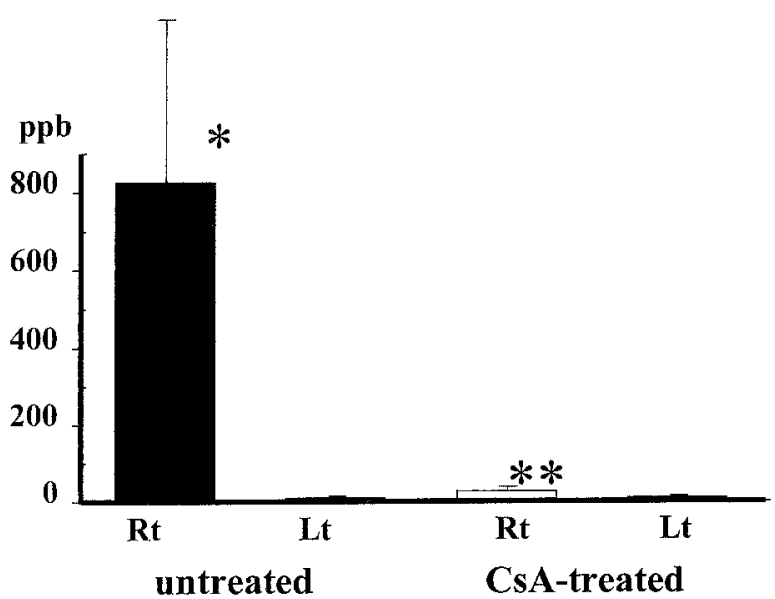

Fig. 3. Exhaled NO concentrations from right $(R t)$ and left $(L t)$ lungs in untreated (solid bars, $n=5$ ) and cyclosporine (CSA)-treated (open bars, $n=4$ ) allografts. ${ }^{*} p=0.0118 ; * * p=0.0199$ versus left lungs.

among the isografts control and cyclosporinetreated and untreated groups. The difference from the previous study may have been caused by the different strain combination. Also, it is conceivable that in lung transplantation a significant part of endogenous NO is lost through ventilation instead of degrading to nitrite/nitrate as in other types of organ transplantation. Because we used right instead of left lung transplantation, the loss of NO by ventilation from the right lungs may have been more efficient than that from the left because the right lung has 1.5 times as much volume as the left.

The cell sources of NO production in grafts are not clear in this study. In rat renal transplantation, Cattell and associates ${ }^{12}$ found that the localization of iNOS in the rejecting grafts was detected in infiltrating mononuclear cells in the glomeruli and interstitium of rejecting kidney by immunohistochemistry and that the great majority of interstitial mononuclear cells in diffuse infiltrates were macrophages. In the respiratory tract, NOS can be induced in various superficial cells, including macrophages, epithelial cells, and infiltrating inflammatory cells. In rat sepsis models treated by intravenous administration of endotoxin, anti-iNOS labeled activated rat macrophages strongly. ${ }^{13}$ Those authors also reported that one type of NOS that shares epitopes with iNOS in macrophages is present constitutively in bronchial epithelium. ${ }^{13}$ Although it is possible that NO produced by the bronchial epithelial cells also plays a role in lung allograft rejection, the amount of NO produced via the constitutive path-
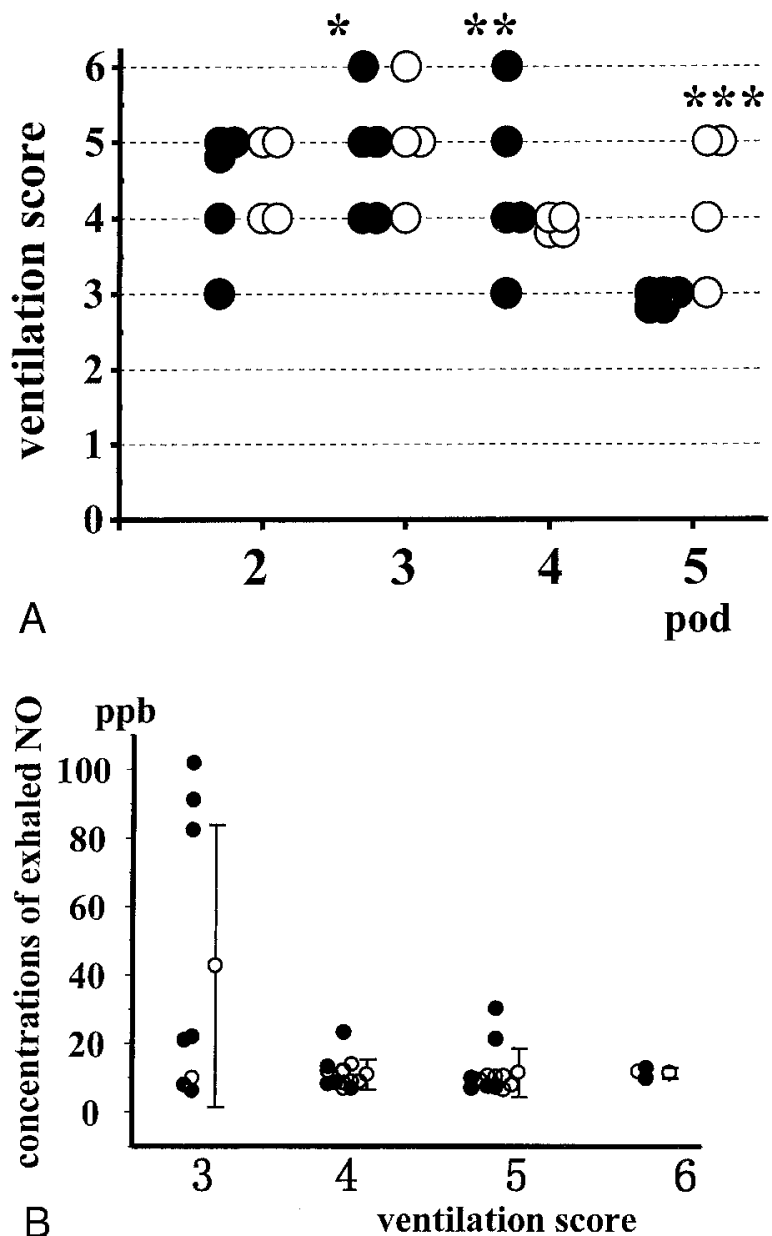

Fig. 4. A, Ventilation scores of untreated (closed circles, $n=5$ ) and cyclosporine-treated (open circles, $n=4$ ) allografts. ${ }^{*} p=0.005 ; * * p=0.0182$ versus day 5 in untreated allografts; ${ }^{* * *} p=0.0281$ versus day 5 in untreated allografts. pod, Postoperative day. B, No significant correlation was seen between ventilation score and the concentrations of exhaled NO.

way can be rather small compared with that produced via the inducible pathway. In chronic rejection of lung allografts, however, alloimmunoreactive sites are focused in the bronchial epithelium, especially in bronchioles as the most important site of bronchiolitis obliterans. A further study is underway to determine the localization of iNOS in chronic and in acute rejection.

In allograft rejection, the role of NO production still remains to be defined. In an in vitro study, Hoffmann and coworkers ${ }^{14}$ reported that proliferation of rat splenocytes was inhibited by a high level of nitrite/nitrate in the culture supernatants and that this inhibition was reversed by addition of $\mathrm{N}^{\mathrm{G}}$ - 
$\underline{\mathrm{A}}$

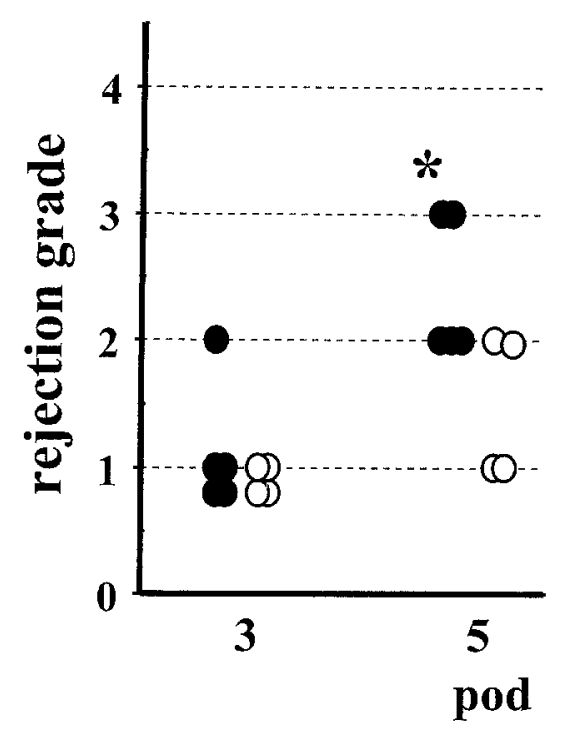

$\underline{B}$

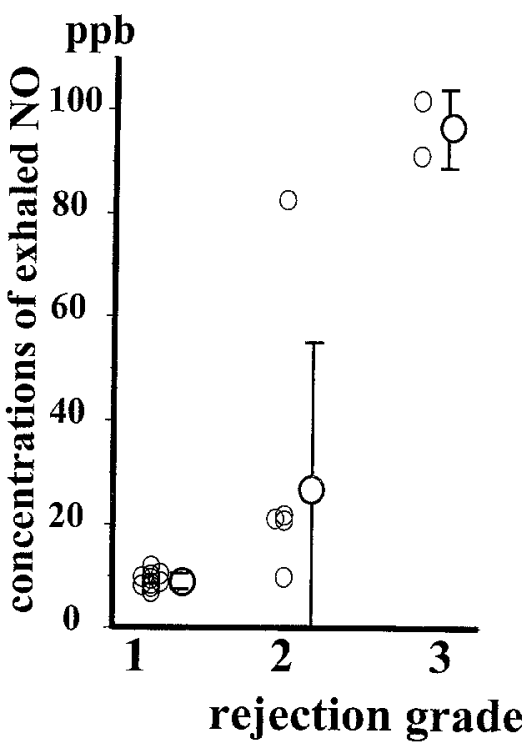

Fig. 5. A, Histologic rejection grade of untreated (closed circles, $n=5$ ) and cyclosporine-treated (open circles, $n=4$ ) allografts. ${ }^{*} p=0.0139$ versus day 3 in untreated allografts. pod, Postoperative day. B, Correlation between rejection grade and the concentrations of exhaled NO. $p=0.0001$ with Spearman's correlation coefficient by rank.

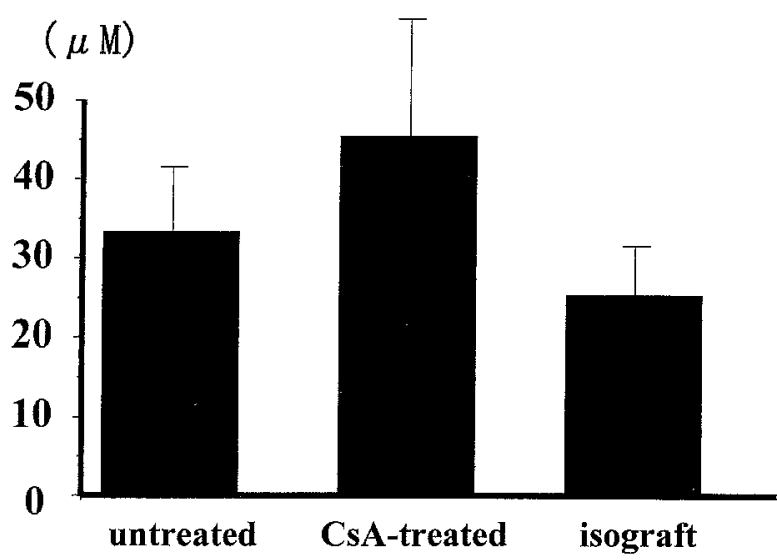

Fig. 6. Serum nitrite/nitrate concentrations in untreated allografts $(n=5)$, cyclosporine (CsA)-treated allografts $(n=4)$, and control isografts $(n=4)$. There were no significant differences among groups.

monomethyl-L-arginine, the competitive inhibitor of NOS. In contrast, Worrall and associates ${ }^{15}$ found in an in vivo study that treatment with aminoguanidine, the preferential inhibitor of iNOS, prolonged graft survival in rat heart transplantation, reduced the histologic rejection grades, and inhibited the increase in systemic serum nitrite/nitrate levels. In rat lung transplantation, Shiraishi and colleagues ${ }^{4}$ also reported that administration of aminoguanidine prolonged graft survival and attenuated histologic rejection grades and serum nitrite/nitrate levels. On the other hand, although NO inhalation therapy for injured lung during the immediate posttransplantation stage has been recommended, ${ }^{16}$ there has not been any report that inhalation of NO accelerates acute lung rejection. Whether NO produced in the rejecting graft is cytoprotective or cytotoxic is still a matter of controversy.

In clinical lung transplantation, diagnosis of acute rejection is one of the most important subjects. It has been common to use clinical findings such as deterioration in arterial oxygenation, fever, increasing fatigue, and radiographic infiltrates or hilar flare to detect acute rejection. ${ }^{17}$ Therefore we studied whether the ventilation score as a clinical standard and the histologic rejection grade as the gold standard for diagnosis of rejection correlated with the level of exhaled NO in untreated and cyclosporinetreated allografts. There was no significant correlation between the ventilation score and the concen- 
trations of exhaled NO because some grafts on early postoperative days showed decreased aeration and density caused not by the progression of allograft rejection but by reperfusion injury, atelectasis, or retention of plural effusion. This was suggested by the findings at rethoracotomy and determination of histologic rejection grade; that is, all allografts showed grade A1 rejection except for one recipient that showed grade $\mathrm{A} 2$ on day 3 (Fig. $5, A$ ). However, the concentration of exhaled NO significantly correlated with the progression of allograft rejection assessed by histologic study (Fig. 5, B). This suggests that exhaled NO could be a useful marker for allograft rejection in lung transplantation. However, we must realize that various situations that compromise the respiratory tract such as infection, inflammatory reactions, and rejection should be differentiated in the clinical setting.

Despite these limitations, measurement of the level of NO in exhaled air is noninvasive and rapid and could be considered a useful method to detect and follow up allograft rejection before the use of a more invasive measure such as transbronchial or open lung biopsy in the clinical setting.

\section{REFERENCES}

1. Langrehr JM, Murase N, Markus PM, et al. Nitric oxide production in host-versus-graft and graft-versus-host reactions in the rat. J Clin Invest 1992;90:679-83.

2. Winlaw DS, Schyvens CG, Smythe GA, et al. Urinary nitrate excretion is a noninvasive indicator of acute cardiac allograft rejection and nitric oxide production in the rat. Transplantation 1994;58:1031-6.

3. Tanaka S, Kamiike W, Ito S, et al. Generation of nitric oxide as a rejection marker in rat pancreas transplantation. Transplantation 1995;60:713-7.

4. Shiraishi T, DeMeester SR, Worrall NK, et al. Inhibition of inducible nitric oxide synthase ameliorates rat lung allograft rejection. J Thorac Cardiovasc Surg 1995;110:1449-60.

5. Kharitonov SA, Yates D, Robbins RA, Logan-Sinclair R,
Shinebourne EA, Barnes PJ. Increased nitric oxide in exhaled air of asthmatic patients. Lancet 1994;343:133-5.

6. Stewart TE, Valenza F, Ribeiro SP, et al. Increased nitric oxide in exhaled gas as an early marker of lung inflammation in a model of sepsis. Am J Respir Crit Care Med 1995;151: 713-8.

7. Mizuta T, Nakahara K, Matsumura A, Minami M, Yoon HE, Matsuda $H$. Comparison of early postoperative hemodynamics of left and right single lung transplants after contralateral pulmonary artery ligation in the rat. Transplant Proc 1995; 27:585-6.

8. Prop JM, Ehrie MG, Crapo JD, et al. Reimplantation response in isografted rat lungs: analysis of causal factors. J Thorac Cardiovasc Surg 1984;87:702-11.

9. Yousem SA, Berry GJ, Brunt EM, et al. A working formulation for the standardization of nomenclature in the diagnosis of heart and lung rejection: Lung Rejection Study Group. J Heart Lung Transplant 1990;9:593-601.

10. Green LC, Wagner DA, Glogowski J, et al. Analysis of nitrate, nitrite and $[15 \mathrm{~N}]$ nitrate in biological fluids. Anal Biochem 1982;126:131-8.

11. National Academy of Sciences. Guide for the care and use of laboratory animals. Bethesda, Maryland: National Institutes of Health. NIH publication No. 86-23, revised 1985.

12. Cattell V, Smith J, Jansen A, Moreno VR, Moncada S. Localization of inducible nitric oxide synthase in acute renal allograft rejection in the rat. Transplantation 1994;58:1399402.

13. Kobzik L, Bredt DS, Lowenstein CJ, et al. Nitric oxide synthase in human and rat lung: immunocytochemical and histochemical localization. Am J Respir Cell Mol Biol 1993; 9:371-7.

14. Hoffman RA, Langrehr JM, Billiar TR, Curran RD, Simmon RL. Alloantigen-induced activation of rat splenocytes is regulated by the oxidative metabolism of L-arginine. J Immunol 1990;145:2220-6.

15. Worrall NK, Lazenby WD, Misko TP, et al. Modulation of in vivo alloreactivity by inhibition of inducible nitric oxide synthase. J Exp Med 1995;181:63-70.

16. Date H, Triantafillou AN, Trulock EP, et al. Inhaled nitric oxide reduces human lung allograft dysfunction. J Thorac Cardiovasc Surg 1996;111:913-9.

17. Cooper JD, Patterson GA, Trulock EP, et al. Results of single and bilateral lung transplantation in 131 consecutive recipients. J Thorac Cardiovasc Surg 1994;107:460-71. 